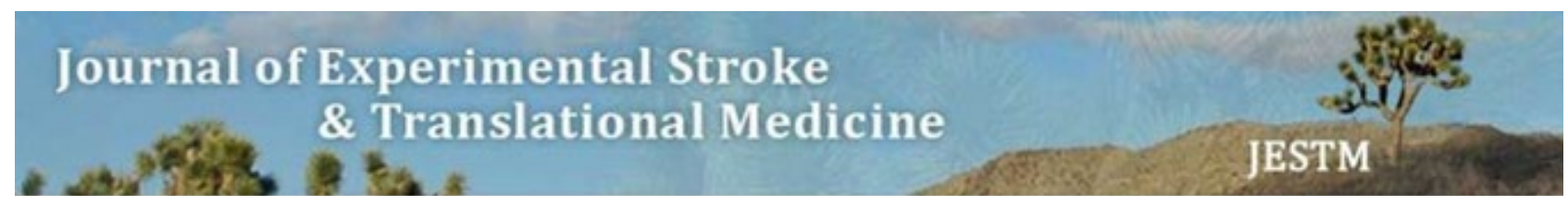

\title{
Effects of Real-time Auditory Stimulation Feedback on Balance and Gait after Stroke: a Randomized Controlled Trial
}

March 27, $2016 \cdot$ Volume $9 \cdot$ Original Research

Chul-Ho Yang ${ }^{1}$, Jung-Hee Kim¹, Byoung-Hee Lee ${ }^{2 *}$

${ }^{1}$ Graduate School of Physical Therapy, Sahmyook University, Seoul, Republic of Korea

2 Department of Physical Therapy, Sahmyook University, Seoul, Republic of Korea

Article Citation: Byoung-Hee Lee, Jung-Hee Kim, Chul-Ho Yang. Effects of Real-time Auditory Stimulation Feedback on Balance and Gait after Stroke: a Randomized Controlled Trial. J Exp Stroke Transl Med. 2016 February. Online access at www.jestm.com

Correspondence should be sent to: Byoung-Hee Lee, Department of Physical Therapy, Sahmyook University, Hwarangro-815, Nowongu, Seoul, Republic of Korea, Tel: 8223399634, Fax: 8223991639, E-mail: 3679@syu.ac.kr

\section{Abstract}

Background: The aim of this study was to examine the effects of Real-time Auditory stimulation Feedback (RAF) on balance and gait in stroke patients and to suggest a more effective method of gait training.

Methods: This was a hospital-based, randomized controlled trial with a blinded assessor. Twenty four chronic stroke patients who were more than six months post-stroke participated in this study. They were randomly allocated to 1 of 2 groups: Real-time Auditory stimulation Feedback (RAF) group $(n=12)$ and treadmill group $(n=12)$. Patients in the RAF group received three $30-$ minute sessions of treadmill gait training combined with RAF per week over a period of four weeks. Patients in the treadmill group received general treadmill training under the same experimental condition without RAF. The following clinical measures were used for assessment of static balance and gait abilities: Balancia, Timed Up and Go Test. Spatiotemporal gait parameters were also collected using the GAITRite system.

Results: Significant differences in outcomes for average perturbation velocity and total perturbation distance in closed eyes condition were observed in the RAF group compared with the control group. In addition, measurements for the TUG test indicated significant differences in the RAF group. Results for gait speed, step length and stride length, single limb support percentage of the affected side, and gait asymmetry showed a more significant difference in the RAF group compared with the control group.

Conclusion: Gait training using RAF is effective for restoration of balance and gait ability, and it improves the existing problem of rhythmic auditory stimulation gait training.

Key Words: Rhythm Auditory Stimulation, Stroke, Balance, Gait, Treadmill

\section{Background}

The main goal of rehabilitation in stroke patients is a recovery of social activity and physical function. There are various physical therapeutic interventions that are generally used to improve balance and walking ability in stroke patients: task-oriented approach [Van Peppen RP et al., 2004], motor imagery training [Dickstein R et al., 2004], functional electrical stimulation [Robbins SM et al., 2006], robot-assisted training with virtual reality [Mirelman A et al., 2009], rhythmic auditory stimulation [Hayden R et al.,2009,Pelton TA et al., 2010], and treadmill training [Hesse S, 2008,Patterson SL et al., 2007].

Rhythmic auditory stimulation (RAS), designed to improve motor control ability, is a therapeutic intervention based on music therapy that facilitates physical movement by giving an auditory stimulation on the brain areas that control motor function. RAS training is used in patients with stroke, Parkinson disease and traumatic brain injury, and also elderly people who have shown decreased ability to walk. The goal of this training is to help them adapt to their own gait pattern and make a stable recovery [Kwak EE, 2007].Many studies mentioned above have demonstrated that RAS training is an effective way to improve walking ability, gait asymmetry, step length, and gait speed in stroke patients [Hayden R et al.,2009, Kwak EE, 2007,Roerdink M et al., 2007].

However, the studies also reported that they had difficulty in synchronizing between auditory stimulation and gait pattern in stroke patients. Therefore, this study aims to examine the effects of Real-time Auditory stimulation Feed-back (RAF) training on balance and gait in stroke patient and suggest a more effective way of gait training by improving the existing problem of RAS training.

\section{Methods}

\section{Subjects}

Twenty-four stroke patients voluntarily participated in this study. All participants signed an informed consent form after they received information about the purpose and procedure of the experiment, and use of data. The inclusion criteria were [Van Peppen RP et al., 2004] six months or more after stoke onset, [Dickstein R et al., 2004] scores above 24 on the K-MMSE, [Robbins SM et al., 2006] ability to understand verbal instructions, [Mirelman A et al., 2009] ability to walk independently for at least 10 minutes, [Hayden R et al.,2009] no 
orthopedic problems in lower limbs, [Pelton TA et al., 2010] no sensory problems that can affects walking ability. The present study was approved by Sahmyook University Institutional Review Boards and each subject was able to follow instructions and gave informed consent by signing an approved consent form; thus, the rights of human subjects were protected.

\section{Experimental procedures}

24 participants were randomly assigned with computer lottery to RAF treadmill gait training group $(n=12)$ and general treadmill gait training group $(n=12)$. To start the RAF treadmill training, foot switches were attached to the participants' heel and Microsoft visual $C++2011$ software was operated. When participants started to walk and make an initial contact on their less affected side, the software sensed the foot pressure through the foot switch and provided real-time auditory stimulation for the participants. When gait sensor system sensed five consecutive pressure signals, participants were provided with auditory stimulation in two sounds of different pitch with reduced speed by half of the average gait speed from the initial contact of sixth phase of the gait cycle. Therefore, when the sound and the actual step were not synchronized, the tempo in auditory stimulation was automatically set to a new cadence of participants, and then RAS could be continued.

The first stage of the training was a warm-up process, treadmill gait without RAF. Its purpose was to increase muscle tension and facilitate neuromuscular system to walk. The second stage was treadmill gait training with RAF for 10 minutes, followed by 2 minutes of break. After repeating the same process twice, treadmill gait training was conducted without RAF for the last 4 minutes. Then the participants were instructed to walk without any auditory stimulation. The training was conducted for 30-minute session, three sessions per week over four weeks.

During the first week, participants received treadmill training with RAF that adjusted to the average speed of five consecutive initial contacts with consideration for safety and physical adaptation of participants. From the second to the fourth week, treadmill training with RAF was conducted with $5 \%$ increase in average speed.

Participants in the general treadmill gait training group received treadmill gait training under the same experimental environments except for RAF. All the participants in both groups received 30-minute sessions of conventional physical therapy for 10 times per week for 4 weeks. The proprioceptive neuromuscular facilitation based on traditional motor control theory and motor learning theory was applied as a conventional physical therapy. The main reasons for 2 drop-outs from the study were a discharge before the intervention period and a personal issue (Figure 1)

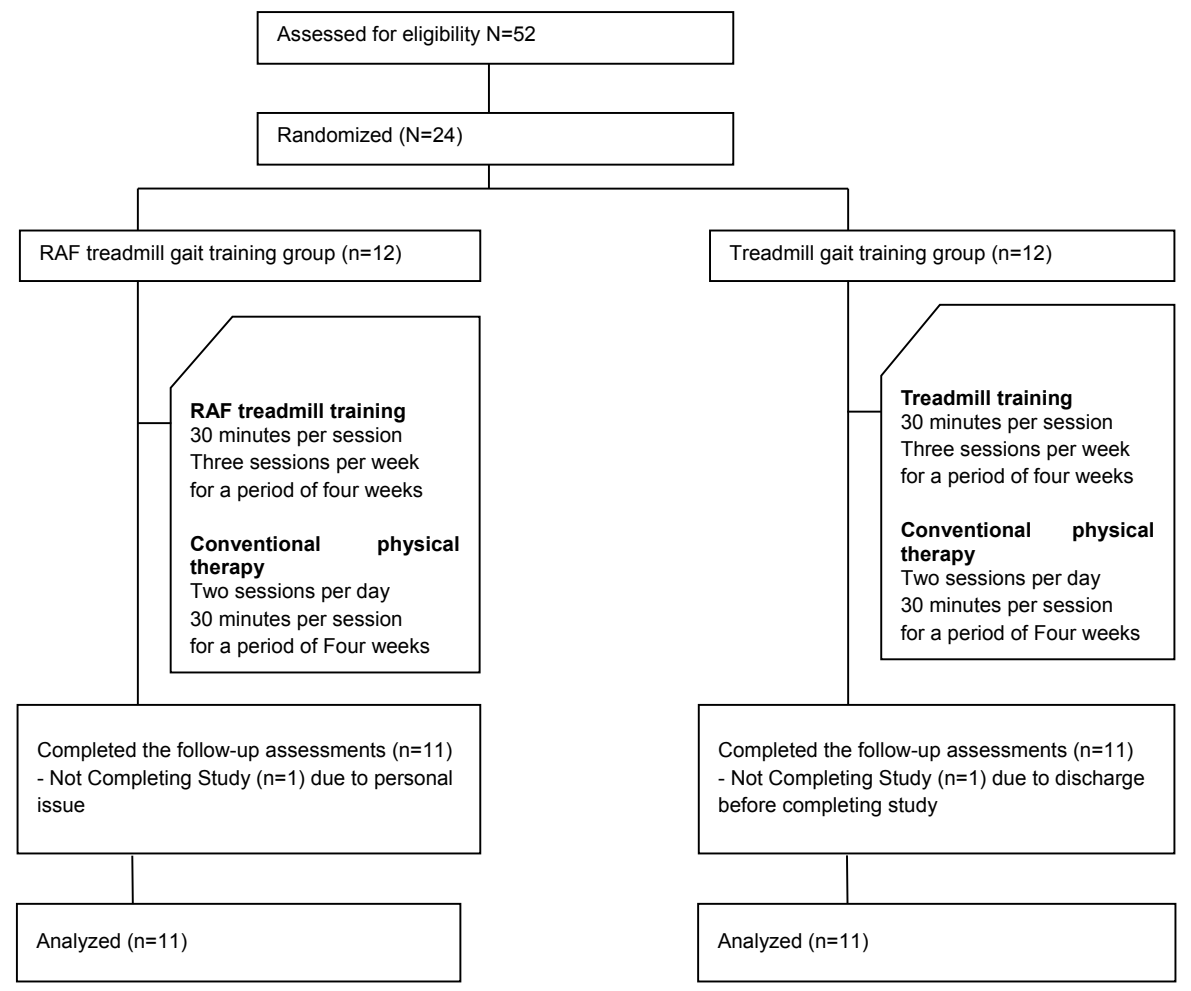

\section{Figure 1.}

Flow of participants through the training program

\section{Outcome measurements}

Balancia, equipment for measuring perturbation and postural control, was used to measure static balance in a standing position. It was composed of Wii balance board and laptop with built-in Bluetooth. Balancia software ver. 1.0 (Balancia software ver 1.0, Mintosys, Korea, 2011) was used for analyzing the measured data. Participants were asked to stand barefoot on the Wii balance board in a comfortable position with eyes opened. In this study, total perturbation distance and average perturbation velocity were measured with Balancia software. 
Timed up and Go test (TUG test) were conducted to evaluate dynamic balance ability of the participants. The test was conducted 3 times and the average time was used for analyzing. Intra-rater reliability $(r=.99)$ and inter-rater reliability $(r=.98)$ were assessed [Flansbjer UB et al., 2008].

The GAITRite system (CIR System Inc. Clifton, USA) was used for analysis of spatiotemporal gait parameters. Patients walk along the walkway at the most comfortable velocity according to the verbal sign of the tester. GAITRite GOLD, Version 3.2b (CIR system Inc, USA) software was used for processing of information on the collected temporal and spatial variable. Interrater reliability of the GAITRite was .92 for healthy subjects [van Uden CJ et al., 2004], Gait asymmetry was assessed by comparing the swing times performed by one leg with respect to those performed by the other using the following formula [Plotnik M et al., 2007]: Gait Asymmetry =100×|In(SSWT/ LSWT)|where SSWT and LSWT stand for mean value of swing time for the leg with the short and long mean swing time, respectively [Plotnik M et al., 2007].

\section{Statistical analysis}

SPSS statistical software (ver. 18.0) was used for statistical analysis of all data. Shapiro-Wilk was used to test for normality of variables and general characteristics of participants. Descriptive statistics were used for analyzing general characteristics of participants. Paired $\mathrm{t}$ test was conducted to compare the differences between pre and post training in each group, and independent $t$ test was conducted to compare between-group differences. The level of statistical significance was set at 05 .

\section{Results}

Baseline characteristics of the 22 patients who completed the experiment are shown in (Table 1). There were no significant differences of sex, Paretic side, Stroke type, age, height, weight, MMSE and duration after onset in baseline characteristics between the groups.

\begin{tabular}{|c|c|c|c|}
\hline \multirow{2}{*}{\begin{tabular}{|l|} 
Characteristics \\
Sex(male/female $)$ \\
\end{tabular}} & \multirow{2}{*}{$\begin{array}{c}\text { RAF group }(n=11) \\
9 / 2\end{array}$} & Treadmill group $(n=11)$ & \multirow{2}{*}{$\frac{p}{1.000}$} \\
\hline & & $9 / 2$ & \\
\hline \multicolumn{4}{|l|}{ Paretic side (n) } \\
\hline right/left & $7 / 4$ & $6 / 5$ & .682 \\
\hline \multicolumn{4}{|l|}{ Stroke type } \\
\hline (hemorrhagic/infarction) & $7 / 4$ & $6 / 5$ & .682 \\
\hline Age (year) & $51.91(13.30)$ & $55.82(13.58)$ & .503 \\
\hline Height (cm) & $166.55(6.36)$ & $167.09(7.71)$ & .858 \\
\hline Weight (kg) & $67.00(11.07)$ & $64.00(8.52)$ & .485 \\
\hline MMSE (score) & $27.64(1.56)$ & $27.45(1.86)$ & .807 \\
\hline After onset(month) & $11.18(3.68)$ & $11.97(3.53)$ & .642 \\
\hline
\end{tabular}

Table 1.

General characteristics of participants $(\mathrm{N}=22)$

RAF group showed a more significant decrease in average perturbation velocity than those of the control group in opened eyes condition. The results of RAF group showed a more significant decrease in average perturbation velocity than those of the control group in closed eyes condition. A more significant decrease in total perturbation distance was shown in RAF group, compared to those of the control group in closed eyes condition. A more significant decrease in dynamic balance was shown in RAF group, compared to those of the control group in Timed up and Go test (Table 2).

\begin{tabular}{|c|c|c|c|c|c|c|c|}
\hline \multirow{2}{*}{\multicolumn{2}{|c|}{ Parameters }} & \multicolumn{4}{|c|}{ Values } & \multicolumn{2}{|c|}{ Change values } \\
\hline & & \multicolumn{2}{|c|}{ RAF group (n=11) } & \multicolumn{2}{|c|}{ Treadmill group $(n=11)$} & \multirow{2}{*}{$\begin{array}{c}\text { RAF group } \\
(n=11)\end{array}$} & \multirow{2}{*}{$\begin{array}{c}\text { Treadmill } \\
\text { group }(n=11) \\
\text { post-pre }\end{array}$} \\
\hline & & pre & post & pre & post & & \\
\hline \multirow[t]{2}{*}{$\begin{array}{l}\text { Eye opened } \\
\text { condition }\end{array}$} & $\begin{array}{l}\text { Average perturbation } \\
\text { velocity }(\mathrm{cm} / \mathrm{s})\end{array}$ & $2.55(.51)$ & $2.16(.35)^{*}$ & $2.74(.72)$ & $2.69(.71)$ & $-.39(.40) \dagger$ & $-.05(.32)$ \\
\hline & $\begin{array}{l}\text { Average total perturbation } \\
\text { distance }(\mathrm{cm})\end{array}$ & $76.95(15.28)$ & $66.58(11.09)^{*}$ & 74.91(16.72) & $73.75(15.54)$ & $-10.37(12.05) \dagger$ & $-1.15(9.32)$ \\
\hline \multirow[t]{2}{*}{$\begin{array}{l}\text { Eye closed } \\
\text { condition }\end{array}$} & $\begin{array}{l}\text { Average perturbation } \\
\text { velocity }(\mathrm{cm} / \mathrm{s})\end{array}$ & $3.02(.83)$ & $2.14(.40)^{*}$ & $3.14(.61)$ & $2.94(.63)$ & $-.88(.75)$ & $-.19(.44)$ \\
\hline & $\begin{array}{l}\text { Average total perturbation } \\
\text { distance }(\mathrm{cm})\end{array}$ & $90.91(24.81)$ & $65.86(12.38)^{*}$ & $86.70(18.03)$ & 81.64(16.64) & $-25.05(6.72) \dagger$ & $-5.06(13.12)$ \\
\hline \multicolumn{2}{|c|}{ Timed up and Go test (sec) } & $23.73(10.57)$ & $19.82(18.38)^{*}$ & $24.82(9.67)$ & $23.36(9.65)$ & $-3.90(2.62) \dagger$ & $-1.45(2.42)$ \\
\hline
\end{tabular}

\section{Table 2.}

Comparisons of balance between the group $(\mathrm{N}=22)$

The results of spatio-temporal gait parameters within-group are shown in (Table 3). When comparing the differences in outcomes before and after the intervention within each group, the RAF group showed significant changes in Gait speed, Cadence, Step length of paretic side, Stride length of paretic side, Percentage of single limb support of paretic side and Gait asymmetry after the intervention period. In the differences between-group, there was a more significant difference in spatiotemporal gait parameters of RAF group compared to control group. 


\begin{tabular}{|c|c|c|c|c|c|c|}
\hline \multirow[t]{3}{*}{ parameters } & \multicolumn{4}{|c|}{ Values } & \multicolumn{2}{|c|}{ Change values } \\
\hline & \multicolumn{2}{|c|}{ RAF group $(n=11)$} & \multicolumn{2}{|c|}{ Treadmill group $(n=11)$} & \multirow{2}{*}{$\begin{array}{c}\text { RAF } \\
\text { group(n=11) } \\
\text { post-pre }\end{array}$} & \multirow{2}{*}{$\begin{array}{c}\text { Treadmill } \\
\text { group(n=11) } \\
\text { post-pre }\end{array}$} \\
\hline & pre & post & pre & post & & \\
\hline Gait speed $(\mathrm{cm} / \mathrm{s})$ & $41.15(20.16)$ & $75.00(24.67)^{\star}$ & $42.92(20.24)$ & $45.81(22.40)$ & 15.84(10.73)† & $2.90(6.06)$ \\
\hline Cadence(steps/min) & $71.53(17.94)$ & $82.22(18.50)^{*}$ & $73.99(20.50)$ & $75.26(20.39)$ & 10.69(7.86)† & $1.27(3.78)$ \\
\hline Step length of paretic side $(\mathrm{cm})$ & $33.18(7.34)$ & $40.76(8.95)^{\star}$ & $33.35(8.82)$ & $34.76(11.26)$ & $7.58(5.88) \dagger$ & $1.41(3.28)$ \\
\hline Stride length of paretic side $(\mathrm{cm})$ & $66.85(15.23)$ & $80.04(17.62)^{*}$ & $68.77(19.51)$ & 71.31(22.99) & 13.18(9.93)† & $2.54(6.19)$ \\
\hline $\begin{array}{l}\text { Percentage of single limb } \\
\text { support of paretic side (\%GC) }\end{array}$ & $27.02(7.30)$ & $30.77(6.88)^{\star}$ & $30.75(6.74)$ & $31.27(6.24)$ & $3.75(3.25) \dagger$ & $0.52(3.94)$ \\
\hline Gait asymmetry & $25.14(10.21)$ & $18.87(8.24)^{*}$ & $24.30(8.13)$ & $22.98(8.34)$ & $-6.27(6.73) \dagger$ & $-1.32(3.48)$ \\
\hline
\end{tabular}

Values are means (SD). ${ }^{*} p<.05$ : significant difference within group. $\dagger p<.05$ : significant difference between groups.

\section{Table 3.}

Comparisons of spatio-temporal gait parameters between the groups $(\mathrm{N}=22)$

\section{Discussion}

It has been generally known that rhythmic auditory stimulation training and treadmill training are both effective to promote normal gait pattern through providing the repetitive and intensive stimulus for motor areas in the brain [Hesse S, 2008,Thaut MH et al., 2007].Studies on RAS training have shown that when different tempos of rhythmic stimuli were given, the faster tempo led to increase in cadence and step and decrease in GA, resulting in the positive effects on recovery of gait ability [Plotnik M et al., 2007, Arias P et al., 2008, Hausdorff JM et al., 2007,Willems AM et al., 2006]. The stability of inter limb coordination was more improved when RAS was provided on both paretic and non-paretic side, compare with non-paretic side only [Roerdink $\mathrm{M}$ et al., 2009].

However, as mentioned above, it has been observed that it is difficult to increase the synchronicity between rhythmic stimulation and gait pattern of participants in RAS training. Therefore, the main contribution of this study compared with previous RAS studies is that it has examined RAF as an effective way for adjusting to irregular gait pattern of participants during RAS training

Center of gravity (COG) perturbation and TUG test have been conducted to identify changes in balance, and RAF group has shown significant improvement in balance. As reported by Braun et al (2007), the result has indicated that learned response to balance during the gait training has caused increase in dynamic balance and decrease in perturbation distance [Braun SM et al., 2007].It has also indicated that treadmill training has provided repetitive exercise and facilitated accuracy in participant's lower limb movements [Yang YR et al., 2008], and that it has increased the stability in lower limb through the improvement of lower limb symmetry, eventually improving their balancing abilities [Silver $\mathrm{KH}$ et al., 2000].

The results of this study have shown that the cadence increases as gait speed increases. It can be interpreted that it is because the lengthened single limb support and stance phase on the affected side has created a symmetrical gait cycle, which has led to improvement of lower limb. This result has been consistent with that of previous studies indicating that increased treadmill speed has brought increase in cadence 10

It has been known that RAF has positive effects on improvement in symmetry of initial contact of both legs and increases gait speed15. It can be concluded that the effects of RAF lead to significant increase in step length, stride length, and single limb support. It has also been known that as the tempo of RAS gets faster, step and stride length increase, and it leads to improvement of GA. The measurement outcomes of this study and Roredink et al (2007) show decrease in GA by 6.27 in RAF group and 2.32 in treadmill gait training group. This demonstrates that treadmill gait training combined with RAF is a more effective way to improve the GA and the spatiotemporal gait ability in stroke patients [Roerdink M et al., 2007].

After the 3weeks of training, RAF group shows significant changes in balance and gait ability [Thaut MH et al., 2007], whereas treadmill training group shows only temporary improvement in gait pattern and is unable to expect long-term effects and recovery of gait ability.

This study has limitations in regards of participant selection. First, the number of participants were not enough to generalize the outcomes of the study because of the small sample size. But this study has clinical significance and implications for practical therapy due to minimized biases ranging from sampling and random assignment to training environment. Second, the outcomes of this study cannot be applied to all stroke patients consistently because this study focuses on chronic patients 6 months after stroke onset. Therefore, further study is needed to generalize the clinical implication of the study by varying stroke length and increasing the number of participants

\section{Conclusion}

This study has been conducted to solve the problem of RAS: The desynchronicity between the actual gait and auditory stimulation. And it has been demonstrated that the RAS training is effective for static balance and spatiotemporal gait parameters in stroke patients, and this result has been supported by researches in rehabilitation and many other academic studies on therapeutic interventions. Therefore, the RAS training combined with RAF can be applied as an effective method for the improvement in static balance, and in spatiotemporal gait parameters within stroke patients.

\section{References}

Van Peppen RP, Kwakkel G, Wood-Dauphinee S, Hendriks HJ, Van der Wees PJ, et al. (2004) The impact of physical therapy on functional outcomes after stroke: what's the evidence? Clin Rehabil 18: 833-862.

Dickstein R, Dunsky A, Marcovitz E (2004) Motor imagery for gait rehabilitation in post-stroke hemiparesis. Phys Ther 84:1167-1177.

Robbins SM, Houghton PE, Woodbury MG, Brown JL (2006) The therapeutic effect of functional and transcutaneous electric stimulation on improving gait speed in stroke patients: a meta-analysis. Arch Phys Med Rehabil 87: 853-859. 
Mirelman A, Bonato P, Deutsch JE (2009) Effects of training with a robot-virtual reality system compared with a robot alone on the gait of individuals after stroke. Stroke 40:169-174.

Hayden R, Clair AA, Johnson G, Otto D (2009) The effect of rhythmic auditory stimulation (RAS) on physical therapy outcomes for patients in gait training following stroke: a feasibility study. Int J Neurosci 119: 2183-2195.

Pelton TA, Johannsen L, Huiya C, Wing AM (2010) Hemiparetic stepping to the beat: asymmetric response to metronome phase shift during treadmill gait. Neurorehabil Neural Repair 24: 428-434.

Hesse S (2008) Treadmill training with partial body weight support after stroke: a review. NeuroRehabilitation 23: 55-65.

Patterson SL, Forrester LW, Rodgers MM (2007) Determinants of walking function after stroke: differences by deficit severity. Arch Phys Med Rehabil 88: 115-119.

Kwak EE (2007) Effect of rhythmic auditory stimulation on gait performance in children with spastic cerebral palsy. J Music Ther 44:198216.

Roerdink M, Lamoth CJ, Kwakkel G, van Wieringen PC, Beek PJ (2007) Gait coordination after stroke: benefits of acoustically paced treadmill walking. Phys Ther 87:1009-1022.

Flansbjer UB, Miller M, Downham D, Lexell J (2008) Progressive resistance training after stroke: effects on muscle strength, muscle tone, gait performance and perceived participation. J Rehabil Med 40:42-48

van Uden CJ, Besser MP (2004) Test-retest reliability of temporal and spatial gait characteristics measured with an instrumented walkway system (GAITRite). BMC Musculoskelet Disord 5:13.

Plotnik M, Giladi N, Hausdorff JM (2007) A new measure for quantifying the bilateral coordination of human gait: effects of aging and Parkinson's disease. Exp Brain Res 181: 561-570.

Thaut MH, Leins AK, Rice RR (2007) Rhythmic auditory stimulation improves gait more than NDT/Bobath training in near-ambulatory patients early poststroke: a single-blind, randomized trial. Neurorehabil Neural Repair 21: 455-459.

Arias P, Cudeiro J (2008) Effects of rhythmic sensory stimulation (auditory, visual) on gait in Parkinson's disease patients. Exp Brain Res 186: $589-601$

Hausdorff JM, Lowenthal J, Herman T, Gruendlinger L, Peretz C, et al. (2007) Rhythmic auditory stimulation modulates gait variability in Parkinson's disease. Eur J Neurosci 26: 2369-2375.

Willems AM, Nieuwboer A, Chavret F (2006) The use of rhythmic auditory cues to influence gait in patients with Parkinson's disease, the differential effect for freezers and non-freezers, an explorative study. Disabil Rehabil 28: 721-728.

Roerdink M, Lamoth CJ, van Kordelaar J (2009) Rhythm perturbations in acoustically paced treadmill walking after stroke. Neurorehabil Neural Repair 23: 668-678.

Braun SM, Beurskens AJ, van Kroonenburgh SM, Demarteau J, Schols JM, et al. (2007) Effects of mental practice embedded in daily therapy compared to therapy as usual in adult stroke patients in Dutch nursing homes: design of a randomised controlled trial. BMC Neurol $7: 34$

Yang YR, Tsai MP, Chuang TY, Sung WH, Wang RY (2008) Virtual reality-based training improves community ambulation in individuals with stroke: a randomized controlled trial. Gait Posture 28: 201-206.

Silver KH, Macko RF, Forrester LW, Goldberg AP, Smith GV (2000) Effects of aerobic treadmill training on gait velocity, cadence, and gait symmetry in chronic hemiparetic stroke: a preliminary report. Neurorehabil Neural Repair 14:65-71. 